\title{
BMJ Open Supporting the use of theory in cross- country health services research: a participatory qualitative approach using Normalisation Process Theory as an example
}

\author{
Catherine A O'Donnell, ${ }^{1}$ Frances S Mair, ${ }^{1}$ Christopher Dowrick, ${ }^{2}$ \\ Mary O’Reilly-de Brún, ${ }^{3}$ Tomas de Brún, ${ }^{3}$ Nicola Burns, ${ }^{1,4}$ Christos Lionis, ${ }^{5}$ \\ Aristoula Saridaki, ${ }^{5}$ Maria Papadakaki, ${ }^{5,6}$ Maria van den Muijsenbergh, ${ }^{7,8}$ \\ Evelyn van Weel-Baumgarten, ${ }^{7}$ Katja Gravenhorst, ${ }^{2}$ Lucy Cooper, ${ }^{2}$ \\ Christine Princz, ${ }^{9}$ Erik Teunissen, ${ }^{7}$ Francine van den Driessen Mareeuw, ${ }^{7}$ \\ Maria Vlahadi, ${ }^{5}$ Wolfgang Spiegel, ${ }^{9}$ Anne MacFarlane ${ }^{10}$
}

To cite: O'Donnell CA, Mair FS, Dowrick C, et al. Supporting the use of theory in crosscountry health services research: a participatory qualitative approach using Normalisation Process Theory as an example. BMJ Open 2017;7:e014289. doi:10.1136/ bmjopen-2016-014289

- Prepublication history and additional material are available. To view these files please visit the journal online (http://dx.doi. org/10.1136/bmjopen-2016014289).

Received 15 September 2016 Revised 28 April 2017 Accepted 2 May 2017

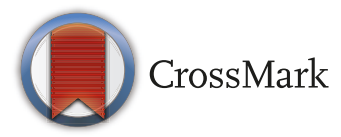

For numbered affiliations see end of article.

Correspondence to

Professor Catherine A 0'Donnell; Kate.0'Donnell@glasgow.ac.uk

\section{ABSTRACT}

Objectives To describe and reflect on the process of designing and delivering a training programme supporting the use of theory, in this case Normalisation Process Theory (NPT), in a multisite cross-country health services research study.

Design Participatory research approach using qualitative methods.

Setting Six European primary care settings involving research teams from Austria, England, Greece, Ireland, The Netherlands and Scotland.

Participants RESTORE research team consisting of 8 project applicants, all senior primary care academics, and 10 researchers. Professional backgrounds included general practitioners/family doctors, social/cultural anthropologists, sociologists and health services/primary care researchers.

Primary outcome measures Views of all research team members $(n=18)$ were assessed using qualitative evaluation methods, analysed qualitatively by the trainers after each session.

Results Most of the team had no experience of using NPT and many had not applied theory to prospective, qualitative research projects. Early training proved didactic and overloaded participants with information. Drawing on RESTORE's methodological approach of Participatory Learning and Action, workshops using role play, experiential interactive exercises and light-hearted examples not directly related to the study subject matter were developed. Evaluation showed the study team quickly grew in knowledge and confidence in applying theory to fieldwork. Recommendations applicable to other studies include: accepting that theory application is not a linear process, that time is needed to address researcher concerns with the process, and that experiential, interactive learning is a key device in building conceptual and practical knowledge. An unanticipated benefit was the smooth transition to cross-country qualitative coding of study data.
Strengths and limitations of this study

- The training programme was developed to support the use of a midlevel theory in six European countries with different primary care systems and cultures.

- Training development, delivery and evaluation engaged with a multidisciplinary team of clinical and non-clinical researchers encompassing multiple professional disciplines.

- Evaluation and careful monitoring of the training alerted us to delivery challenges and facilitated the development of a participatory approach to learning.

- The group of researchers involved in the design and feedback evaluation was relatively small.

- Training focused on one theory-Normalisation Process Theory - but has resulted in a set of generic recommendations.

Conclusion A structured programme of training enhanced and supported the prospective application of a theory, NPT, to our work but raised challenges. These were not unique to NPT but could arise with the application of any theory, especially in large multisite, international projects. The lessons learnt are applicable to other theoretically informed studies.

\section{INTRODUCTION}

Bridging the research to practice gap is a recognised problem in health services research. ${ }^{2}$ One important solution is to underpin such research with strong theoretical approaches. ${ }^{1} 4$ Advantages include providing a framework that is generalisable across settings and individuals, incremental generation of knowledge and a guide for analysis. ${ }^{356}$ Theory can also enhance our 
understanding of the barriers to research translation and implementation and alert us to the context into which new interventions and services are placed.$^{6-9}$ However, many interventions and services are implemented with little or no attention to theory. ${ }^{35}$ When theories are used, they often guide analysis rather than inform the design and conduct of the overall study. ${ }^{51011}$ This may be due, in part, to recognised challenges in applying theory to health services research.

\section{Challenges in using theory in health services research}

The first challenge is a lack of conceptual clarity as to what a 'theory' is. McDonald describes theory as 'an organized, heuristic, coherent, and systematic articulation of a set of statements related to significant questions. providing a generalizable form of understanding, ${ }^{12}$ There are three recognised levels of 'theory'. Grand theory is abstract and broadly applicable across different areas and subjects. ${ }^{612} 13$ The next level, mid-range or 'big theory', is less abstract, addressing specific phenomena and concepts that can be incorporated into testable propositions or questions and inform intervention development. ${ }^{6}{ }^{12}$ The third level, programme theory, is often considered as 'small' theory, specifying particular components of an intervention in logic models and explicitly linking a programme's processes and inputs to its intended outcomes. ${ }^{614}$

The second challenge is to decide which theory best informs the work being conducted. For example, theory can focus on: explaining individual behaviours and responses (eg, theory of planned behaviour); understanding organisational responses (eg, diffusion of innovation); dissemination (eg, streams of policy process); or implementation (eg, Promoting Action on Research Implementation in Health Services or PARIHS).$^{15}$ While theoretical choice is informed by the research, the disciplinary composition and background of the research team is also influential. ${ }^{16}{ }^{17}$ Health services research is often multidisciplinary and draws on many fields including sociology, psychology, biostatistics, health economics and clinical disciplines. This requires teams to understand and respect each other's theoretical and paradigmatic positions. ${ }^{3}$ The final challenge is a lack of guidance in applying theory to studies. ${ }^{718}$

\section{The application of theory in practice}

Consideration has been given to how research teams could apply theory in practice. For example, the Reach, Effectiveness, Adoption, Implementation and Maintenance (RE-AIM) framework was developed for use in the evaluation of public health programmes and interventions but is now widely applied. ${ }^{19}{ }^{20}$ RE-AIM focuses researchers' attention on: population reach; the intervention's adoption, implementation and effectiveness; and, finally, on its maintenance in practice. ${ }^{20}$ The developers of RE-AIM have released training and support for other researchers (http://www.re-aim.hnfe.vt.edu/). However, even with such training available, it is not always applied consistently. Gaglio identified 71 papers published between 1999 and 2010 that used RE-AIM ${ }^{20}$; of these, 'reach' was the most frequently reported dimension, with 'maintenance' reported least often. There was also variation in the reporting of the individual components of each construct. Most reporting was quantitative, with little qualitative research to explore how components were used or understood.

Similar results were reported for the PARIHS framework, which describes several interacting components including clinical and patient experience, local context, culture and leadership, and facilitation. ${ }^{21}$ Again, there was variation in its use across studies, with a lack of detail on the application of different subcomponents to fieldwork. ${ }^{18} 22$ Two other reviews examined the application of the Knowledge to Action (KTA) Framework ${ }^{23}$ and Normalisation Process Theory ${ }^{24}$ to implementation studies. In both, the authors found stability in the application of the high level constructs across studies but, again, variation in researchers' attention to the subconstructs of each. This lack of 'theory fidelity' has been raised in other fields, notably health promotion. ${ }^{23} 25$

Translating the constructs of a chosen theory into interventions can be challenging, especially when applied across multiple research sites. ${ }^{5} 723$ Research teams must be comfortable and aligned with the use of the selected theory and in agreement about the meaning and application of its individual components or constructs. Such challenges are enhanced when teams are working in different settings, countries and across cultural and language boundaries as construct understanding and implementation are likely to be both culturally and context dependent. This mirrors challenges identified in conducting qualitative research across different settings. ${ }^{26}$ These challenges faced the EU-funded RESTORE (REsearch into implementation STrategies to support patients of different ORigins and language background) project, a multisite implementation study across six European countries (box 1). ${ }^{27}$ Focused on cross-cultural communication in primary care, the design and analysis of RESTORE was underpinned throughout by a recognised midlevel, sociological theory-NPT. However, the application of theory to a research study was a new concept for many members of the team. As a result, we had to develop a training programme to familiarise and support the team in this process.

The aim of this paper is to describe and reflect on the process of designing training in the use of theory in a multisite cross-country research project. We discuss the challenges this brought as well as the benefits. Finally, we make recommendations that could be applied to other theoretically driven health services research located in multiple settings, regardless of the theory selected.

\section{METHODS \\ RESTORE study design}

RESTORE was designed and implemented in three stages over 48 months (figure 1) ${ }^{27}$ Stage 1 identified and 
Box 1 Description of the RESTORE project and its underpinning theory, Normalisation Process Theory ${ }^{27}$

RESTORE (REsearch into implementation STrategies to support patients of different ORigins and language background) was focused on the implementation of guidance and training initiatives to support cross-cultural consultations in primary care for vulnerable migrant populations: asylum seekers and refugees, migrants in low paid employment and undocumented migrants. ${ }^{27}{ }^{28}$ Funded by the EU FP7 Programme, RESTORE aimed to bridge the research-practice gap by collecting empirical data on the selection, codesign and implementation of such interventions in five European primary care settings: Austria, England, Greece, Ireland and the Netherlands. A sixth partner, Scotland, focused on the role of the policy environment and health systems of participating countries. ${ }^{29}$

RESTORE used a participatory research approach-Participatory Learning and Action-as its overarching methodological approach, generating rich, in-depth qualitative data. ${ }^{27} 3031$ This involved a range of stakeholders including primary care practitioners, migrant service users, community interpreters and policy makers. To shape the study approach, facilitate data collection and guide the analysis, a robust theoretical approach was essential. For this, we selected Normalisation Process Theory (NPT), a midrange sociological theory concerned with the work that individuals and organisations have to carry out in order to embed and normalise new, complex ways of working into routine practice. ${ }^{32} 33$ NPT operates through four principal constructs or areas of work: coherence (sense-making work); cognitive participation (engagement work); collective action (enacting work); and reflexive monitoring (appraisal work), each with its own set of subconstructs. NPT has been applied to a range of studies, ${ }^{24}$ including guideline implementation, ${ }^{3435}$ treatment burden in chronic disease ${ }^{36-38}$ and evaluating models of care. ${ }^{839}$

recruited key stakeholders in each country, including migrants, community interpreters, primary care practitioners and local policy-makers. An extensive mapping exercise was conducted by each in-country RESTORE team to identify guidance and training initiatives $(\mathrm{G} / \mathrm{TIs})$ supporting intercultural communication in primary care and to assess their initial suitability for implementation. ${ }^{40}$ Stage 2 focused on engaging with local stakeholders to review the identified $\mathrm{G} /$ TIs and democratically select one for implementation by considering the implementation potential of each G/TI. ${ }^{41}$ In Stage 3, the selected G/TI was refined by local stakeholders supported by the in-country RESTORE team, implemented by the stakeholders and RESTORE team, monitored and, where necessary, further refined to improve the chances of sustaining it in routine practice.

Although not entirely linear, the study was designed to broadly align to the four constructs of NPT (figure 2). Stage 1 focused on familiarisation, first on the broad need to apply theory to RESTORE and then with NPT itself. Stage 2 mapped to coherence and cognitive participation; stage 3 mapped to collective action and reflexive monitoring. This structure then influenced the design of the training for the team, which is described below.

\section{The RESTORE team}

The research team of 18 included research and clinical disciplines, with a wide range of expertise and knowledge of the chosen theoretical approach (online supplementary file 1). Three country teams (Austria, Greece and the Netherlands) had no experience of using NPT. Four team members (MacFarlane, Mair, Dowrick and O'Donnell) had extensive experience of using NPT ${ }^{39} 42-44$ including applying NPT prospectively to complex interventions. ${ }^{29}{ }^{45-47}$ These four team members thus formed the NPT trainers group, leading the development and delivery of the training reported here.

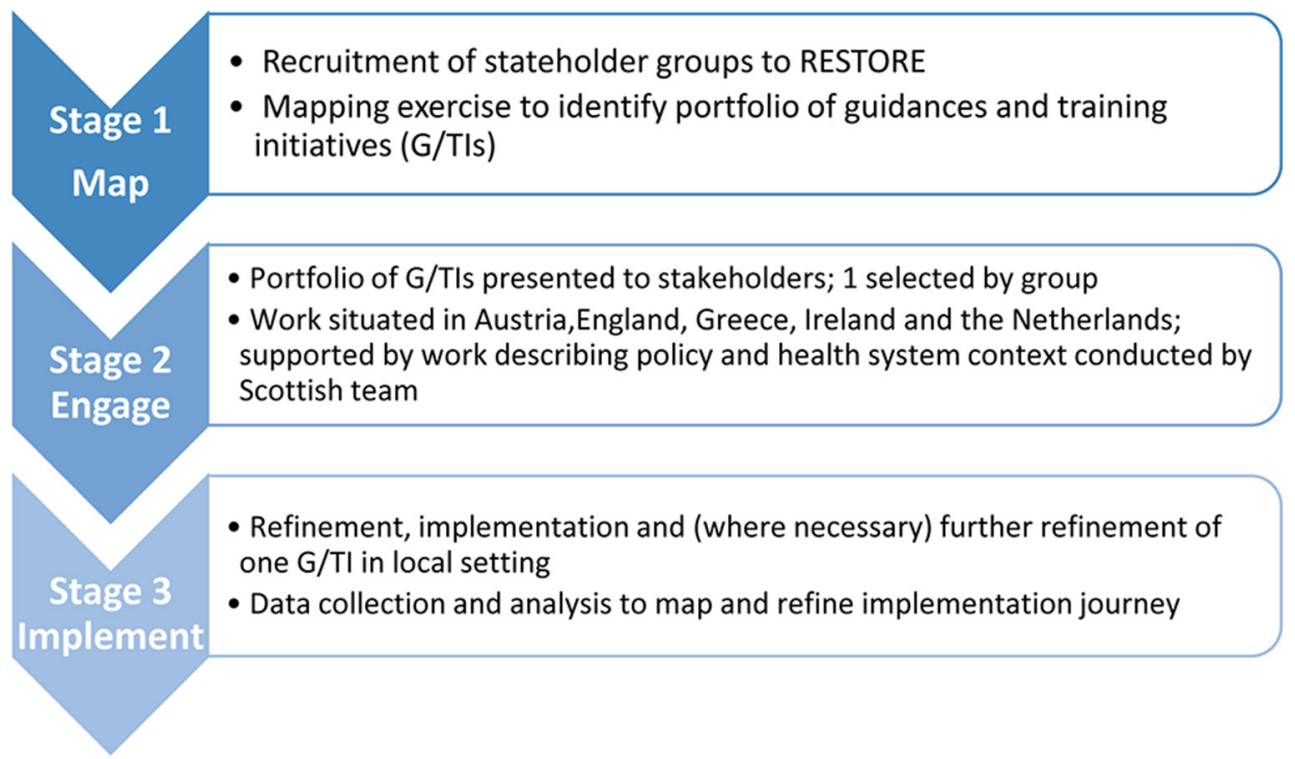

Figure 1 The three stages of RESTORE. RESTORE, REsearch into implementation STrategies to support patients of different ORigins and language background. 


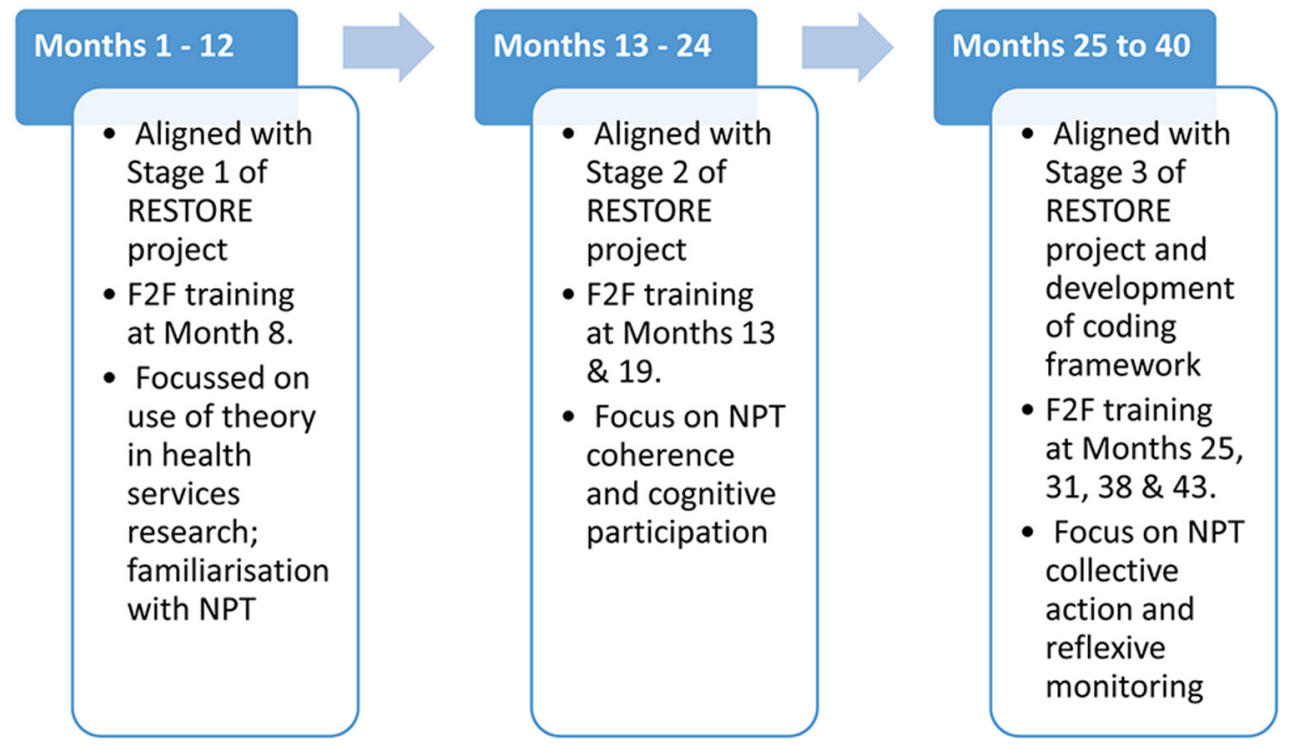

Figure 2 Stages of NPT training and alignment with RESTORE fieldwork. NPT, Normalisation Process Theory; RESTORE, REsearch into implementation STrategies to support patients of different ORigins and language background.

\section{DESCRIPTION OF THE TRAINING PROGRAMME}

Face-to-face training sessions each lasted 1 day. Training content was initially developed by the NPT trainers based on our knowledge of the content that needed to be covered. As time progressed, however, the content was developed based on feedback and evaluation from the RESTORE team members. Here we briefly describe the content of the training sessions. More detailed description of the training sessions and the participatory exercises are contained in online supplementary files 2 and 3; the short presentations can be accessed on Slideshare (see online supplementary file 4 for links).

\section{Early project training (months 1-12)}

Training began at month 8, after the RESTORE researchers had been appointed in each country. In the first session, the rationale for using theory to shape and inform research study design, data collection and analysis was presented. NPT, the theory chosen to underpin RESTORE, was then introduced using previous studies as examples as well as the online NPT toolkit (http:// www.normalizationprocess.org/). Following this, an interactive group exercise helped the research team to consider what issues might arise during the implementation of professional interpreters in primary care. To prompt discussion and improve understanding, the team used a set of 16 NPT-informed questions developed by the NPT trainers along with TdeB. These questions were also being used to guide the early stages of data analysis in the project (table 1). ${ }^{31} 41$

\section{Midproject training (months 13-24)}

At month 13, we focused on the NPT constructs of coherence (sense-making) and cognitive participation (engagement). Learning from early training, we first used a non-RESTORE 'light' example with a humorous exercise that all the team could relate to-namely, could you contemplate staying in a circus tent at a future RESTORE team meeting? (figure 3)

Following this, a RESTORE specific role play was employed to think through the issues of using professional interpreters in a primary care setting; this example drew on team members' own experiences of working with interpreters. Although this was designed to focus the discussion on issues relating to coherence and cognitive participation, issues relating to collective action and reflexive monitoring also arose (see Results).

By month 20, when the next face-to-face training took place, the in-country teams were preparing to commence fieldwork with their stakeholders (stage 2 of RESTORE). Teams were given another opportunity to participate in an interactive role play. For this, a G/TI selected by one of the in-country RESTORE teams in collaboration with their stakeholders was used; some members of the RESTORE team were asked to role play the kind of discussions they might encounter in their fieldwork. The issues and questions that arose during this were recorded and mapped to the four NPT constructs by the other team members, using large wall charts and sticky notelets. The resultant mapping was then reviewed by the NPT trainers and discussed by the group.

\section{Later training sessions (months $\mathbf{2 5 - 4 0 )}$}

By month 25, teams were conducting fieldwork and moving into stage 3 , where the chosen $\mathrm{G} / \mathrm{TI}$ would be fully adapted, implemented and the result of that implementation monitored. This process and the results are reported in two recent RESTORE project papers. ${ }^{41}{ }^{48}$ Teams were now generating qualitative data about that process, which required the development of a coding framework broadly applicable across all the participating sites. Thus, training focused both on the constructs of collective action and reflexive monitoring and on the process of analysis. 
Table 1 NPT constructs and subconstructs as applied to RESTORE ${ }^{3141}$

\begin{tabular}{|c|c|c|c|}
\hline $\begin{array}{l}\text { Coherence } \\
\text { Can stakeholders make } \\
\text { sense of the intervention? }\end{array}$ & $\begin{array}{l}\text { Cognitive participation } \\
\text { Can stakeholders get others } \\
\text { involved in implementing the } \\
\text { intervention? }\end{array}$ & $\begin{array}{l}\text { Collective action } \\
\text { What needs to be done to } \\
\text { make the intervention work } \\
\text { in practice? }\end{array}$ & $\begin{array}{l}\text { Reflexive monitoring } \\
\text { Can the intervention be } \\
\text { monitored and evaluated? }\end{array}$ \\
\hline $\begin{array}{l}\text { Do stakeholders see this as a } \\
\text { new way working? }\end{array}$ & $\begin{array}{l}\text { Do the stakeholders } \\
\text { believe they are the correct } \\
\text { people to drive forward the } \\
\text { implementation? }\end{array}$ & $\begin{array}{l}\text { Does the intervention make it } \\
\text { easier or harder to complete } \\
\text { tasks? }\end{array}$ & $\begin{array}{l}\text { Will stakeholders be able to } \\
\text { judge the effectiveness of the } \\
\text { intervention? }\end{array}$ \\
\hline Individual specification: & & & \\
\hline $\begin{array}{l}\text { Do individuals understand } \\
\text { what tasks the intervention } \\
\text { requires of them? }\end{array}$ & $\begin{array}{l}\text { Are they willing and able } \\
\text { to engage others in the } \\
\text { implementation? }\end{array}$ & $\begin{array}{l}\text { Do those implementing the } \\
\text { intervention have the correct } \\
\text { skills and training for the job? }\end{array}$ & $\begin{array}{l}\text { How will individuals judge } \\
\text { the effectiveness of the } \\
\text { intervention? }\end{array}$ \\
\hline Communal specification: & Activation: & Relational integration: & Communal appraisal: \\
\hline Internalisation: & Legitimation: & Contextual integration: & Reconfiguration: \\
\hline $\begin{array}{l}\text { Do all the stakeholders grasp } \\
\text { the potential benefits and } \\
\text { value of the intervention? }\end{array}$ & $\begin{array}{l}\text { Do they believe it is } \\
\text { appropriate for them to be } \\
\text { involved in the intervention? }\end{array}$ & $\begin{array}{l}\text { Do local and national } \\
\text { resources and policies support } \\
\text { the implementation? }\end{array}$ & $\begin{array}{l}\text { Will stakeholders be able to } \\
\text { modify the intervention based } \\
\text { on evaluation and experience? }\end{array}$ \\
\hline
\end{tabular}

NPT, Normalisation Process Theory; RESTORE, REsearch into implementation STrategies to support patients of different ORigins and language background.

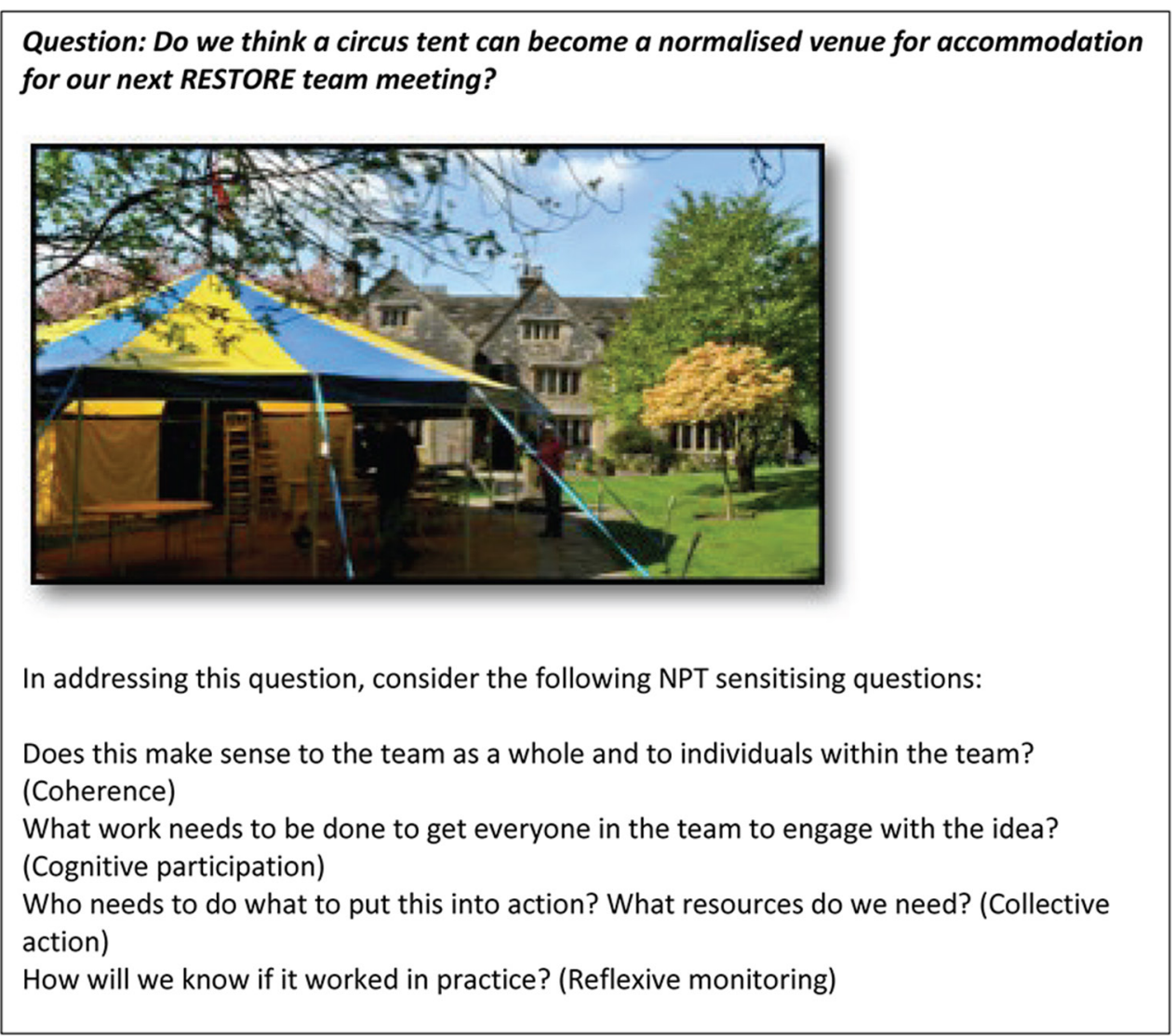

Figure 3 NPT 'light' training material. NPT, Normalisation Process Theory; RESTORE, REsearch into implementation STrategies to support patients of different ORigins and language background. 
To begin training in analysis, an anonymised extract of data generated from RESTORE fieldwork in Ireland was selected. This was precirculated to the teams for coding to the four constructs and, if possible, to the subconstructs. In addition to team coding, the extract was sent to the trainers and to three recognised external experts in NPT. Coded data were collated and presented at the consortium training at month 25.

Training sessions at months 38 and 43 continued to focus on analysis. Teams were asked to review extracts of data or to bring examples of coding dilemmas with them. Coding dilemmas included examples of data that researchers were concerned were being miscoded, data that did not appear to fit into the NPT framework and data that appeared to be particular to only one site. Evaluation at the end of these later sessions allowed the NPT trainers to clarify the team's understanding of the coding process and to address any ongoing concerns through teleconferences or email.

\section{Non-face-to-face support}

Several mechanisms were put into place to support teams in-between face-to-face sessions, including buddy groups (linking teams experienced in theory use with less experienced teams), telephone and video conferences, e-mail feedback on issues and problems. Later in the project, telephone and video conferences were also used to support data analysis, promoting consistency in the application of theory to analysis across the participating countries.

Outside the formal training sessions, we uploaded NPT relevant information such as key papers and links to the NPT toolkit website (www.normalizationprocess.org) to a shared folder accessible by all the research team to serve as a resource whenever required.

\section{Evaluation of the NPT training content}

Face-to-face training was evaluated qualitatively at the end of each training day. Everyone present at the training days (generally all 18 members of the research team) participated in each evaluation; no one refused to participate. Methods included: written lists of the three most positive and three most negative features of the training; speed evaluation where each participant was given $2 \mathrm{~min}$ to verbally record which aspects of training had, or had not, been effective for them; and scoring elements of the training on a Likert scale (eg, from $1=$ very poor to $5=$ very good). These data were collected either as short written comments or recorded on a digital recorder. Additional evaluation was conducted approximately 3 weeks after the first session, when the team were emailed a short set of questions asking what had worked well, what had not worked well and what they wanted from future training sessions. All the evaluation feedback was reviewed by the four members of the training team and the findings summarised into 'what worked', 'what didn't work' and 'what the team would like to do next'. The results of the evaluations were then summarised and presented back to the full team at the next face-to-face RESTORE consortium meeting, providing the team with a further opportunity to comment on whether they believed all the key issues or suggestions regarding training had been captured and addressed.

\section{RESULTS}

\section{Early project training (months 1-12)}

Team evaluation indicated that the content of the first training sessions (sessions 1 and 2, online supplementary file 2) was too didactic and prescriptive. The team felt overwhelmed trying to assimilate general knowledge about the application of theory to research along with NPT-specific information. The early use of the 16 NPT sensitising questions (table 1) was not well liked by some researchers used to more inductive methods of working in qualitative projects. Others, particularly the clinicians, found this approach helpful as they tried to develop their understanding of the theory's different constructs.

The 16 questions of the (NPT) toolkit gave us a better insight into what was meant by terms like 'sensemaking', 'participation', 'action' and 'monitoring' (buddy report from Dutch and English teams)

\section{Midproject training (months 13-24)}

As a result of team feedback on the didactic nature of the first sessions, the NPT trainers adopted a more Participatory Learning and Action (PLA)-focused style for the midproject training sessions. This also reflected the methodological approach of the RESTORE project in the field, as described elsewhere. ${ }^{27}{ }^{31}$ Consequently, later sessions had one or at most two short didactic presentations, with the remaining time spent on participatory exercises. The midproject training content was aligned more closely to the temporal arrangement of the project itself and linked to the overarching constructs of NPT. Thus, we focused principally on sense-making (coherence) and engagement work (cognitive participation) first, before turning to the actual work undertaken (collective action) and, finally, monitoring and appraisal work (reflexive monitoring) (figure 2).

The use of a 'light' humorous exercise, the circus tent (figure 3), where the team could concentrate on the content of the theory without worrying about how it applied to future fieldwork evaluated well. Exercises using practical examples grounded in the fieldwork they would have to conduct during the course of the project were also helpful.

Exercises helped a lot! Very comfortable now! (Anonymous response in written evaluation feedback)

Worked well. I'm beginning to see sense. The use of PLA methods/ techniques really helps grasping NPT and made it digestible! (Anonymous response in written evaluation feedback) 
Interactive exercises and role play designed to focus on coherence and cognitive participation also spontaneously picked up issues relating to collective action (who would actually do the work; how would it be funded) and reflexive monitoring (how would teams know if professional interpreters had an impact). This served as an important reminder that, even when NPT sensitising questions from researchers were designed to focus on sense-making and engagement, other issues would naturally emerge in the discussion, emphasising the lack of linearity in the application of theory to data generation. This was reflected in feedback obtained from two of the in-country teams.

Coherence and cognitive participation refer, in the main, to processes before any implementation work has occurred. However, we did note that the theory is fluid and not fixed or linear, so this means that the experience of doing the implementation work (collective action) and reflecting on that work (reflexive monitoring) could influence coherence and cognitive participation over time. An 'aha!' moment occurred when we distilled the thinking in the group around the difference between cognitive participation and collective action as 'thinking about the doing' and 'doing the doing' (buddy report from Greek and Irish teams)

\section{Later training sessions (months 25-40)}

Training conducted later in the project steadily moved from using theory to inform the collection of data in the field to using theory to underpin analysis of data. Face-toface training session at months 25 and 31 focused mainly on coding data extracts and on round-table discussion of the approach being taken. Prior to meeting at month 25, teams received an extract of data generated by the Irish team (box 2); teams were asked to code this to the main constructs and, if possible, subconstructs of NPT. Coding was then compared at the training session in month 25.

Table 2 shows examples of coding from two of the in-country teams, along with the final coding agreed by the whole RESTORE team. The first coding extract was selected because the data focused mainly on the construct of coherence, that is, developing an understanding of

\section{Box 2 Background to data generation by Irish team}

- MORdeB abd TdeB developed training materials to support the RESTORE researchers use the methods of PLA in their fieldwork. One of these was a DVD in which researchers in Ireland roleplayed a discussion among healthcare professionals, policy-makers, migrants' representatives and interpreters about the implementation of a training initiative to support the use of trained interpreters in primary care consultations in Ireland. Researchers were assigned these roles; the facilitator was one of RESTORE's PLA experts. The role play was filmed and the dialogue trasncribed to allow teams to review and develop experience in applying NPT to coding data. This PLA training will be described more fully in future publications. the rationale for using interpreters in practice and the benefits of that. Overall, there was a high level of agreement between the team in their data coding, particularly when coding to the high-level constructs of NPT. Each in-country team showed a good degree of consistency in coding to the construct of coherence, with some coding in particular to the subconstructs of differentiation ('seeing interpreters as a new way of working') and internalisation ('articulating the benefits of working with interpreters'). The Dutch team also coded this portion of transcript to the construct cognitive participation, suggesting that the conversation was also discussing the need to enrol others into working with interpreters (table 2). Face-to-face discussion at month 25 led to a shared understanding and agreement that-where data were referring to both understanding the use of interpreters and considering who should be involved-then it was appropriate to double code data to both coherence and cognitive participation. Likewise, where resources were referred to, for example the provision of training and DVD materials, text could be coded to collective action (contextual integration). Such discussions both helped the team refine their understanding of NPT, but also resulted in a robust coding framework which could be used across all country teams.

This process continued at later training meetings, at months 31 and 38 supplemented by telephone and video conferences, where coding of data was compared and differences in interpretation were discussed. To facilitate this process, each country team nominated one person to lead on coding qualitative data generated in that country, who then worked with the leads in the other countries to review and discuss coding. Examples of coding were discussed and memos relating to data coding circulated across the team, ensuring consistency of meaning and interpretation in relation to coding data. The final coding frame was then reviewed and discussed at a final training meeting involving all members of the RESTORE team that took place at month 43 .

\section{CHALLENGES}

Ongoing telephone and email contact ensured that difficulties and tensions were quickly surfaced, particularly when theory was being applied to fieldwork. Training at month 20 began with an intensive debriefing, where in-country teams were encouraged to freely discuss their concerns and challenges arising from using NPT. These focused on two related concerns. There was a continued lack of confidence in their knowledge of NPT itself and of being able to correctly map issues and data generated in the field to the NPT constructs. However, the use of visual methods of collecting and displaying data generated during the interactive group exercises, as exemplified in PLA approaches, ${ }^{31}$ meant that the trainers could quickly identify a high degree of fidelity in the assignment of data to NPT constructs, thus reassuring the team of their knowledge development (figure 4). 


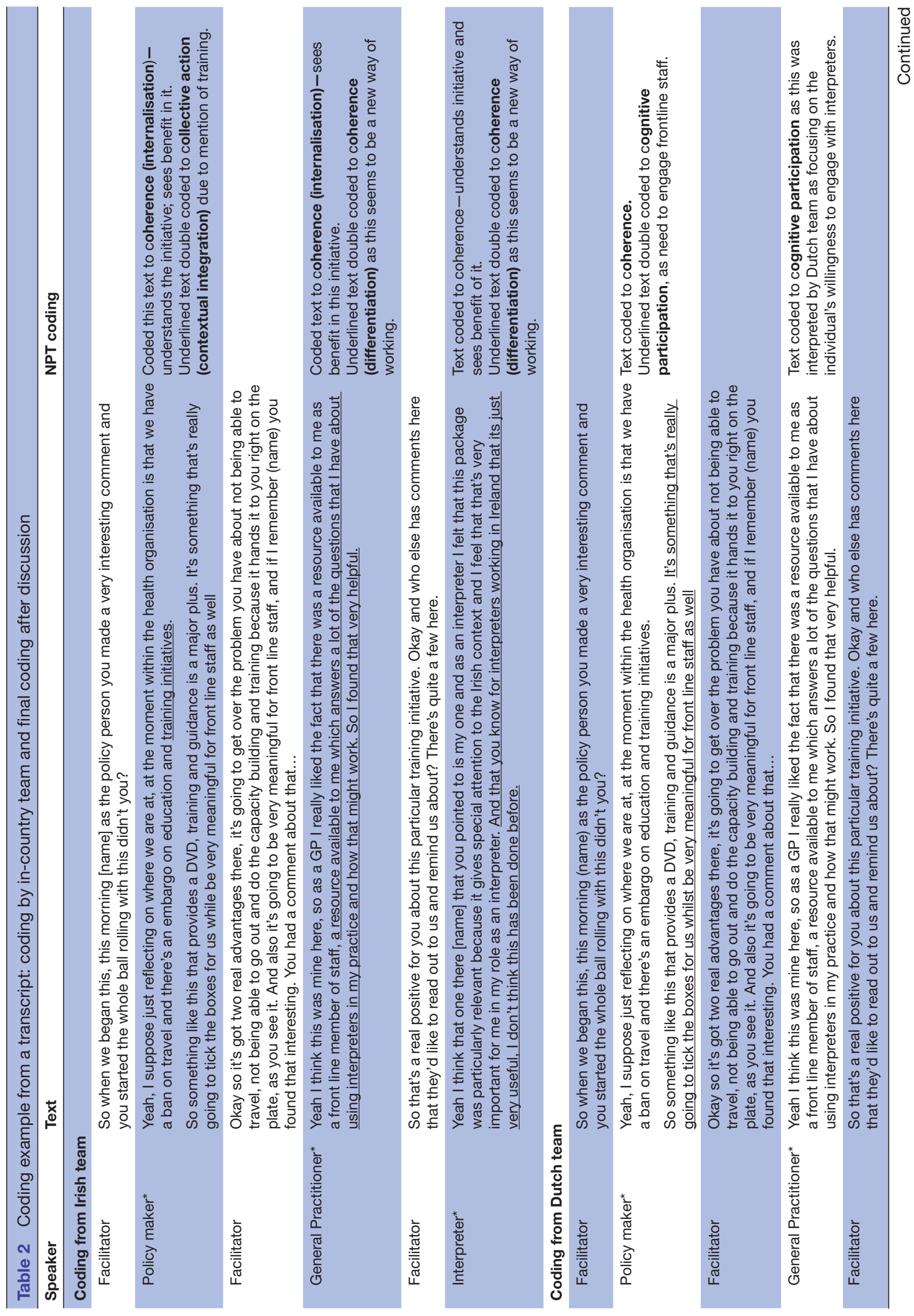

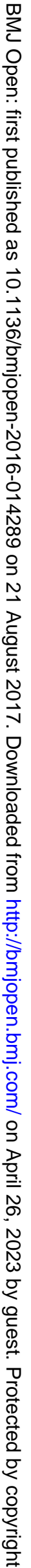




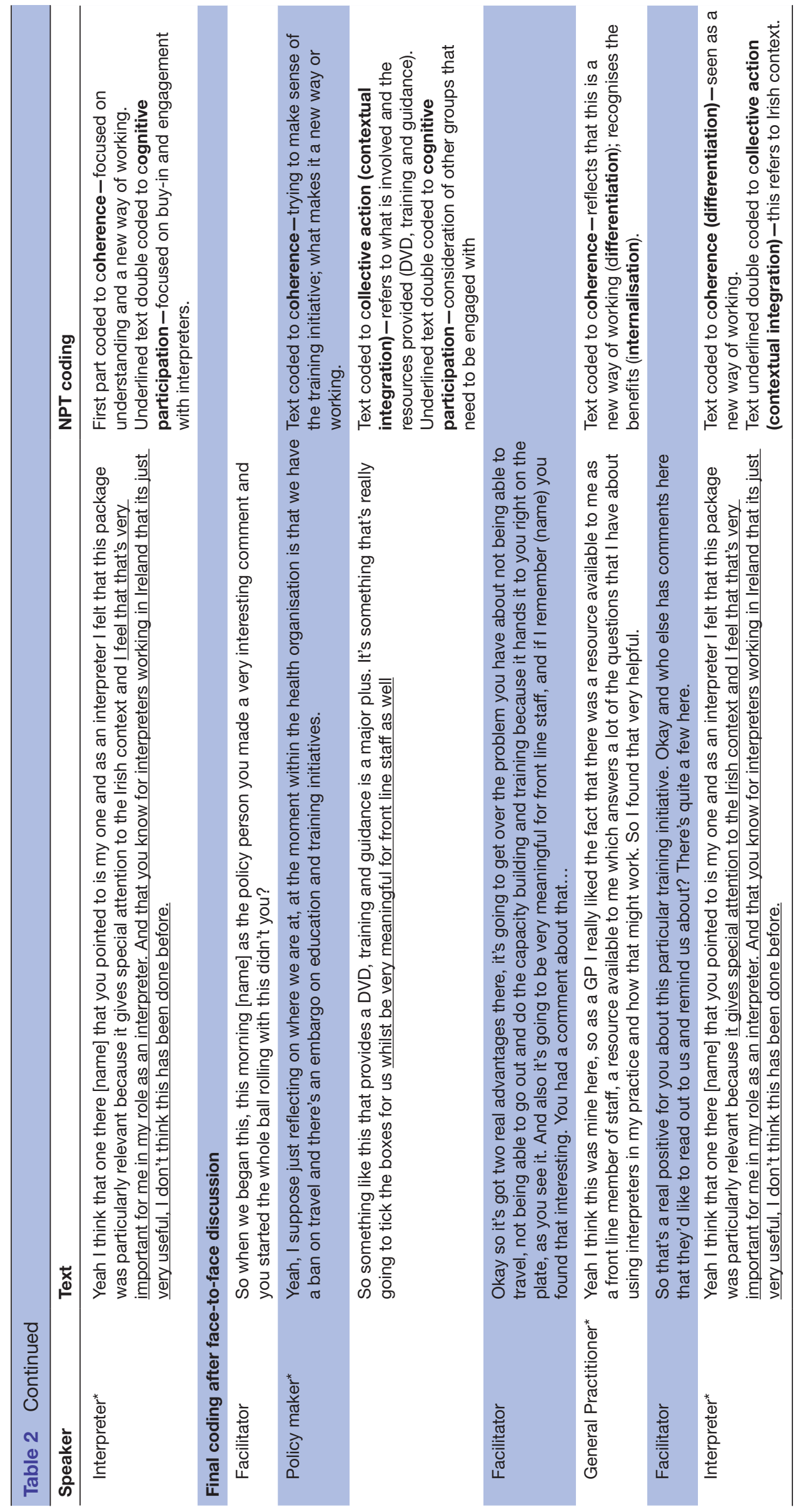




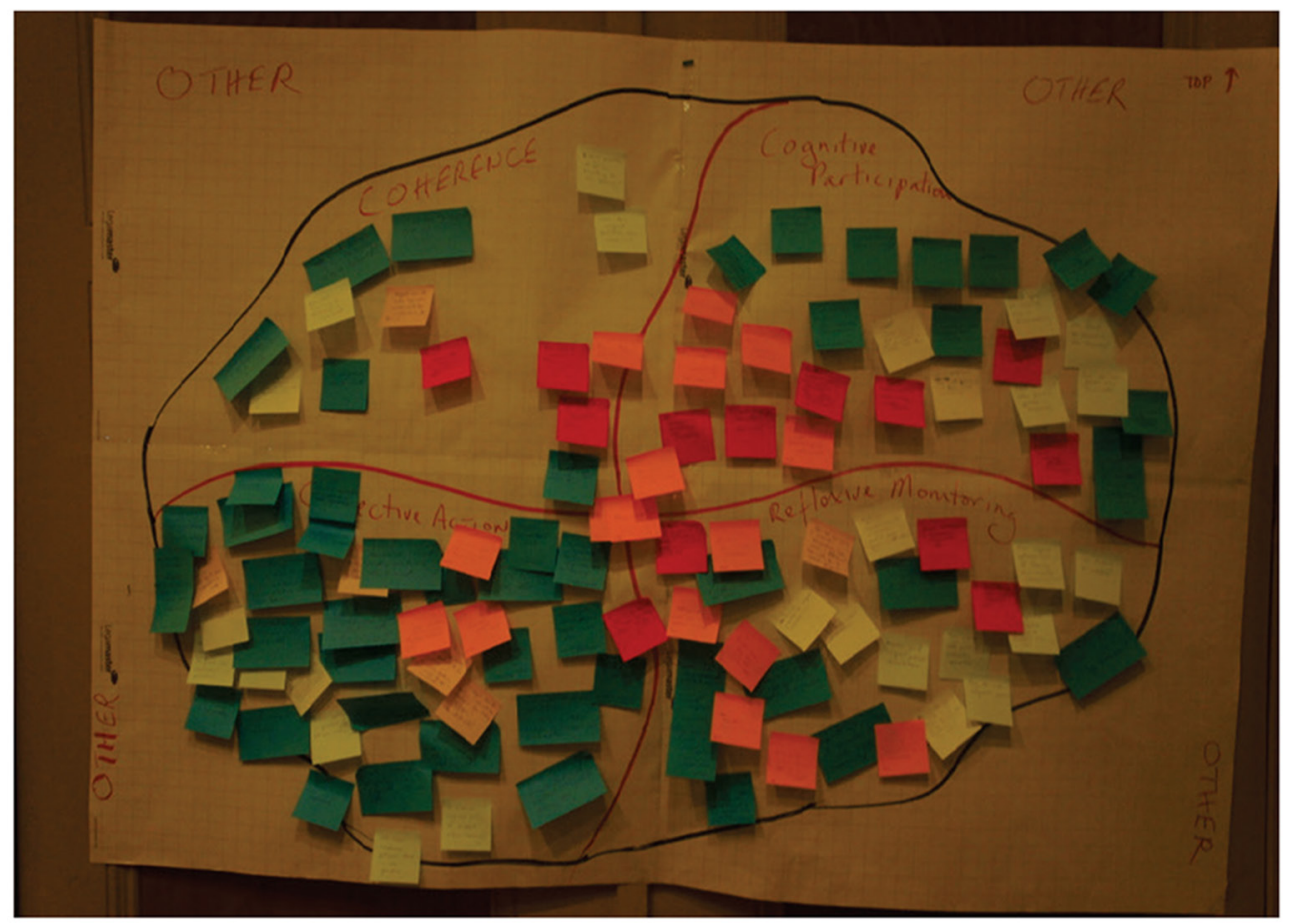

Each "sticky" notelet corresponds to an item of verbal data identified from the interative role play discussion

Figure 4 Example of a visual data mapping exercise.

The second major issue reflected the disciplinary and epistemological differences within the research team. Some researchers were used to policy-related research, where the application of theory to data and the use of approaches such as Framework Analysis ${ }^{49}$ were familiar. Others came from a sociological or anthropological background and were more comfortable with an inductive data-driven approach to analysis. This led to understandable concerns that data might be 'flattened' and shoe-horned into the NPT framework. To alleviate this concern, the trainers paid particular attention to the identification and recognition of coding which lay outside the NPT constructs, for example in relation to power dynamics between different stakeholders. A final concern was whether construct application and data generation, in the field, was linear or whether there were 'feedback loops'. For example, the research team considered the question of whether engaging in the work of implementing a G/TI could increase participants' understanding or 'coherence' in relation to that G/TI? Training, therefore, continuously emphasised the lack of linearity in the process of applying theory to both data collection and analysis and encouraged the researchers to think through how this would affect data collection in the field.

\section{DISCUSSION}

\section{Principal findings and their relation to other work}

We have described our approach to applying a midlevel sociological theory-NPT-to a multisite cross-country research study, RESTORE. In our endeavour to use NPT to shape our overall implementation journey, including data collection as well as analysis, we had to develop iterative and flexible training to support our multidisciplinary, cross-national project team. While this presented challenges, we believe it also strengthened and added value to our work, ensuring it was designed, implemented and analysed in a robust and consistent manner across all five countries in which empirical data collection was conducted.

A multidisciplinary, multinational team inevitably has differences in terms of understanding the process of qualitative research and the use of theory. Professional and cultural perspectives impact on both individual and collective comfort (both in terms of country and professional discipline) with the concept of using theory to inform the design and conduct of a largely qualitative, implementation study. For example, researchers used to a more inductive approach to data analysis were initially cautious of an approach that applied theory to data analysis. The design of a robust programme of training, which acknowledged and discussed these perspectives during the course of the training, was challenging but also allowed the team to reach a shared understanding of what the study was trying to achieve. The benefits of surfacing these tensions became apparent as the training moved to the process of data analysis.

From our experience of developing training for using NPT, we have developed a series of generic recommendations that can be applied to other studies seeking to use theory in health services research (box 3). 
Box 3 Recommendations for the future development of training to support the use of theory in health services research

The application of theory to study design and fieldwork is not linear and training must acknowledge this.

- Experiential learning and the use of interactive, participatory and visual approaches are an important learning device.

- Training can be most effective when it focuses on the high level constructs of a theory.

- Different disciplinary backgrounds must be acknowledged and welcomed.

- Space is required in the training programme to acknowledge and address researcher concerns.

- Training in the application of theory can support the development and robustness of qualitative coding, especially for multisite studies.

A key recommendation is to acknowledge, from the beginning of training, that theory is not linear or sequential. This is often a challenge when applying theory to fieldwork; for example, Michie and colleagues have developed their Behaviour Change model as a wheel, in order to address any preconceived conceptions of 'linearity'. ${ }^{50}$ The model of candidacy has also been criticised for an apparent linearity that is not found when applied in the field. ${ }^{5152}$ The nature and speed of fieldwork means it is important for researchers to be familiar with all constructs of a selected theory, in order to fully appreciate the theoretical relevance of the data as it is generated. Thus, training needs to both acknowledge and affirm the complexities of temporal order in prospective fieldwork and ensure that researchers are familiar with all the components of a theory early enough in the research study to ensure confidence when moving into fieldwork.

Team learning and understanding develops more rapidly and deeply by using participatory and experiential approaches to learning. ${ }^{31}$ In our work, interactive exercises with visual methods of collecting data, role play and non-specific 'light' examples were all effective approaches to supporting learning and understanding. We strongly recommend this approach in the development of training for any complex theory that requires new users to develop an understanding of a range of components. The second advantage of using multiple interactive exercises is as a means to check on research team's 'theoretical fidelity' when analysing the data generated in the field.

Theoretical frameworks are often complex, with constructs that can themselves be broken down to ever smaller subconstructs. This level of complexity can be daunting for researchers new to the theory being used and can lead to difficulties when coding data. Our experience suggests that a focus on the high level constructs of a theory works best in the early stages of training. Once teams have grasped and understood those, they can intuitively develop a deeper understanding of the underlying subcomponents.
Throughout our training programme, we allowed ample time for concerns to be raised and discussed and for the team to develop solutions. An advantage of the time spent of training was apparent; however, later in the project as we moved onto coding the qualitative data generated across multiple sites. By then, the time spent in early training ensured that the team had a much clearer and consistent view of the constructs and their meaning, leading to a consistency and robustness in coding and analysis.

\section{Limitations of the study}

The study is based on the experiences of a single team during one, although large multisite, project. However, the team did represent a diverse range of professional and disciplinary backgrounds, and cultures operating within European primary care settings. The training was focused on the use of only one theoretical framework-NPT-but we believe that the lessons learnt from this and the recommendations arising from the work are applicable to other theoretical frameworks. Finally, although a participatory, qualitative approach was used throughout, we did not have the time within the project to conduct a more in-depth qualitative exploration of the views and experiences of the research team as they applied our chosen theory to the fieldwork.

\section{CONCLUSION}

Overall, we found the prospective application of NPT to our work to be invaluable but, at times, challenging. We believe that these issues were not unique to the use of NPT but could arise with the use of other theories, especially in large multisite and cross-country projects. The development of a complementary package of training to support the use of our chosen theory ensured that our work was consistently and robustly informed by theory at all stages of the project, from design through data collection to analysis. This approach can, and should, be adopted by future research teams carrying out theoretically informed implementation studies.

\section{Author affiliations}

${ }^{1}$ General Practice and Primary Care, Institute of Health and Wellbeing, College of MVLS, University of Glasgow, Glasgow, UK

${ }^{2}$ Institute of Psychology, Health and Society, University of Liverpool, Liverpool, UK ${ }^{3}$ Discipline of General Practice, School of Medicine, National University of Ireland, Galway, Ireland

${ }^{4}$ Faculty of Health and Medicine, Lancaster Medical School, Furness College, University of Lancaster, Lancaster, UK

${ }^{5}$ Faculty of Medicine, University of Crete, Heraklion, Greece

${ }^{6}$ Department of Social Work, School of Health and Social Welfare, Technological

Educational Institute of Crete, Heraklion, Greece

${ }^{7}$ Department of Primary and Community Care, Radboud University Nijmegen

Medical Centre, Nijmegen, The Netherlands

${ }^{8}$ Pharos Centre of Expertise on Health Disparities, Utrecht, The Netherlands

${ }^{9}$ Centre for Public Health, Medical University of Vienna, Vienna, Austria

${ }^{10}$ Graduate Entry Medical School, University of Limerick, Limerick, Ireland

Acknowledgements Some of this work was presented at a workshop at the North American Primary Care Research Group Meeting in November 2014, and we thank 
the participants for their helpful comments; we also thank Professor Carl May, University of Southampton, for his support and helpful discussions. We also thank our reviewers whose insightful comments have enhanced the clarity and order of this paper.

Contributors All authors (CAO, FSM, CD, MOdB, TdB, NB, CL, AS, MP, MvdM, EvW-B, KG, LC, CP, ET, FvdDM, MV, WS and AM) made substantial contributions to the design and development of RESTORE and its training programme, to the collection of data or to the analysis and interpretation of the data. Training materials were developed by CAO, FSM, CD and AM with input from MOdB and TdB. CAO wrote the first draft of the paper and led substantive redrafting, supported by FSM, $\mathrm{CD}$ and $\mathrm{AM}$; all authors listed above were involved in revising and commenting on later drafts of the manuscript. All authors have given their final approval to this version.

Competing interests None declared.

Patient consent Patients not involved in this study.

Provenance and peer review Not commissioned; externally peer reviewed.

Data sharing statement № additional data available. Training materials are available as described in the supplementary files.

Open Access This is an Open Access article distributed in accordance with the Creative Commons Attribution Non Commercial (CC BY-NC 4.0) license, which permits others to distribute, remix, adapt, build upon this work non-commercially, and license their derivative works on different terms, provided the original work is properly cited and the use is non-commercial. See: http://creativecommons.org/ licenses/by-nc/4.0/

(C) Article author(s) (or their employer(s) unless otherwise stated in the text of the article) 2017. All rights reserved. No commercial use is permitted unless otherwise expressly granted.

\section{REFERENCES}

1. Woolf SH. The meaning of translational research and why it matters. JAMA 2008;299:211-3.

2. Pronovost PJ, Goeschel CA. Time to take health delivery research seriously. JAMA 2011;306:310-1.

3. Eccles MP, Armstrong D, Baker R, et al. An implementation research agenda. Implement Sci 2009;4:18.

4. Greenhalgh T, Robert G, Macfarlane F, et al. Diffusion of innovations in service organizations: systematic review and recommendations. Milbank Q 2004;82:581-629.

5. Improved Clinical Effectiveness through Behavioural Research Group (ICEBeRG). Designing theoretically-informed implementation interventions. Implement Sci 2006;1:4.

6. Davidoff F, Dixon-Woods M, Leviton L, et al. Demystifying theory and its use in improvement. BMJ Qual Saf 2015;24:228-38.

7. Sales A, Smith J, Curran G, et al. Models, strategies, and tools. Theory in implementing evidence-based findings into health care practice. J Gen Intern Med 2006;21 Suppl 2:S43-S49.

8. Forster DA, Newton M, McLachlan HL, et al. Exploring implementation and sustainability of models of care: can theory help? BMC Public Health 2011;11 Suppl 5:S8.

9. Craig P, Dieppe P, Macintyre S, et al. Developing and evaluating complex interventions: the New Medical Research Council guidance. Int J Nurs Stud 2013;50:587-92.

10. Davies P, Walker AE, Grimshaw JM. A systematic review of the use of theory in the design of guideline dissemination and implementation strategies and interpretation of the results of rigorous evaluations. Implement Sci 2010;5:14.

11. Colquhoun HL, Brehaut JC, Sales A, et al. A systematic review of the use of theory in randomized controlled trials of audit and feedback. Implement Sci 2013;8:66.

12. McDonald KM, Graham ID, Grimshaw J, et al. Toward a theoretic basis for quality improvement interventions. In: Shojania KG, McDonald KM, Wachter RM, eds. Closing the quality gap: A critical analysis of quality improvement strategies. Rockville, MD: Agency for Healthcare Researchand Quality, 2004:27-40.

13. Nilsen P. Making sense of implementation theories, models and frameworks. Implement Sci 2015;10:53.

14. Weiss $\mathrm{CH}$. Nothing as practical as a good theory: Exploring theorybased evaluation for comprehensive community-based initiatives for children and families. In: Connell JP, Kubisch AC, Schorr LB, eds. Et alNew approaches to evaluating community initiatives, vol 1 concepts, methods and contexts. Washington DC: Aspen Institute, 1995.
15. Tabak RG, Khoong EC, Chambers DA, et al. Bridging research and practice: models for dissemination and implementation research. Am J Prev Med 2012;43:337-50.

16. Grol RP, Bosch MC, Hulscher ME, et al. Planning and studying improvement in patient care: the use of theoretical perspectives. Milbank Q 2007;85:93-138.

17. Wyke S, Adamson J, Dixon D, et al. Consultation and illness behaviour in response to symptoms: a comparison of models from different disciplinary frameworks and suggestions for future research directions. Soc Sci Med 2013;86:-79-87.

18. Ullrich PM, Sahay A, Stetler CB. Use of implementation theory: a focus on PARIHS. Worldviews Evid Based Nurs 2014;11:26-34.

19. Glasgow RE, Vogt TM, Boles SM. Evaluating the public health impact of health promotion interventions: the RE-AIM framework. Am J Public Health 1999;89:1322-7.

20. Gaglio B, Shoup JA, Glasgow RE. The RE-AIM framework: a systematic review of use over time. Am J Public Health 2013;103:e38-e46.

21. Kitson AL, Rycroft-Malone J, Harvey G, et al. Evaluating the successful implementation of evidence into practice using the PARiHS framework: theoretical and practical challenges. Implement Sci 2008;3:1.

22. Helfrich CD, Damschroder LJ, Hagedorn HJ, et al. A critical synthesis of literature on the promoting action on research implementation in health services (PARIHS) framework. Implement Sci 2010;5:82.

23. Field B, Booth A, llott I, et al. Using the knowledge to Action Framework in practice: a citation analysis and systematic review. Implement Sci 2014;9:172.

24. McEvoy R, Ballini L, Maltoni S, et al. A qualitative systematic review of studies using the normalization process theory to research implementation processes. Implement Sci 2014;9:2.

25. Crosby R, Noar SM. Theory development in health promotion: are we there yet? J Behav Med 2010;33:259-63.

26. Benzer JK, Beehler S, Cramer IE, et al. Between and within-site variation in qualitative implementation research. Implement Sci 2013;8:4.

27. MacFarlane A, O'Donnell C, Mair F, et al. REsearch into implementation STrategies to support patients of different ORigins and language background in a variety of European primary care settings (RESTORE): study protocol. Implement Sci 2012;7:111.

28. MacFarlane A, O'Reilly-de Brún M, de Brún T, et al. Healthcare for migrants, participatory health research and implementation science-better health policy and practice through inclusion. The RESTORE project. Eur J Gen Pract 2014;20:148-52.

29. O'Donnell CA, Burns N, Mair FS, et al. Reducing the health care burden for marginalised migrants: the potential role for primary care in Europe. Health Policy 2016;120:495-508.

30. O'Reilly-de Brún M, MacFarlane A, de Brún T, et al. Involving migrants in the development of guidelines for communication in cross-cultural general practice consultations: a participatory learning and action research project. BMJ Open 2015;5:e007092.

31. de Brún T, O'Reilly-de Brún M, O'Donnell CA, et al. Learning from doing: the case for combining normalisation process theory and participatory learning and action research methodology for primary healthcare implementation research. BMC Health Serv Res 2016;16:346.

32. May C, Finch T, Implementing FT. Implementing, embedding, and Integrating Practices: an outline of Normalization process Theory. Sociology 2009;43:535-54.

33. May CR, Mair F, Finch T, et al. Development of a theory of implementation and integration: normalization process Theory. Implement Sci 2009;4:29.

34. Bamford C, Heaven B, May C, et al. Implementing nutrition guidelines for older people in residential care homes: a qualitative study using Normalization process Theory. Implement Sci 2012;7:106

35. May C, Sibley A, Hunt K. The nursing work of hospital-based clinical practice guideline implementation: an explanatory systematic review using Normalisation process Theory. Int J Nurs Stud 2014;51:289-99.

36. Gallacher K, May CR, Montori VM, et al. Understanding patients' experiences of treatment burden in chronic heart failure using normalization process theory. Ann Fam Med 2011;9:235-43.

37. Gallacher K, Morrison D, Jani B, et al. Uncovering treatment burden as a key concept for stroke care: a systematic review of qualitative research. PLoS Med 2013;10:e1001473.

38. Jani B, Blane D, Browne S, et al. Identifying treatment burden as an important concept for end of life care in those with advanced heart failure. Curr Opin Support Palliat Care 2013;7:3-7.

39. Murray E, Treweek S, Pope C, et al. Normalisation process theory: a framework for developing, evaluating and implementing complex interventions. BMC Med 2010;8:63. 
40. de Brún T, de-Brún MO, van Weel-Baumgarten E, et al. Guidelines and training initiatives that support communication in cross-cultural primary-care settings: appraising their implementability using Normalization process Theory. Fam Pract 2015;32:cmv022-5.

41. Lionis $C$, Papadakaki M, Saridaki A, et al. Engaging migrants and other stakeholders to improve communication in cross-cultural consultation in primary care: a theoretically informed participatory study. BMJ Open 2016;6:e010822.

42. May C, Finch T, Mair F, et al. Understanding the implementation of complex interventions in health care: the normalization process model. BMC Health Serv Res 2007;7:148.

43. May CR, Mair FS, Dowrick CF, et al. Process evaluation for complex interventions in primary care: understanding trials using the normalization process model. BMC Fam Pract 2007;8:42.

44. May CR. Assessing and evaluating complex interventions for chronic disease management: the nomalization process model, 2006.

45. Gunn JM, Palmer VJ, Dowrick CF, et al. Embedding effective depression care: using theory for primary care organisational and systems change. Implement Sci 2010;5:62.

46. McEvoy R, MacFarlane A. Community participation in primary care in Ireland: the need for implementation research. Prim Health Care Res Dev 2013;14:126-39.
47. Devlin AM, McGee-Lennon M, O'Donnell CA, et al. Delivering digital health and well-being at scale: lessons learned during the implementation of the dallas program in the United Kingdom. J Am Med Inform Assoc 2016;23:48-59.

48. Teunissen E, Gravenhorst K, Dowrick C, et al. Implementing guidelines and training initiatives to improve cross-cultural communication in primary care consultations: a qualitative participatory european study. Int J Equity Health 2017;16:32.

49. Ritchie J, Spencer L. Qualitative data analysis for applied policy research. In: Bryman A, Burgess RG, eds. Analyzing qualitative data. London: Routledge, 1994:173-94.

50. Michie S, van Stralen MM, West R. The behaviour change wheel: a new method for characterising and designing behaviour change interventions. Implement Sci 2011;6:42.

51. Mackenzie M, Conway E, Hastings A, et al. Is 'Candidacy' a Useful Concept for Understanding Journeys through Public Services? A Critical Interpretive Literature Synthesis. Soc Policy Adm 2013;47:806-25.

52. Mackenzie M, Conway E, Hastings A, et al. Intersections and multiple 'Candidacies': Exploring Connections between Two Theoretical Perspectives on Domestic Abuse and Their Implications for Practicing Policy. Social Policy and Society 2015;14:43-62. 